\title{
Environmental impacts of nanomaterials: providing comprehensive information on exposure, transport and ecotoxicity - the project DaNa2.0
}

\author{
Dana Kühnel ${ }^{{ }^{*}}$, Clarissa Marquardt ${ }^{2}$, Katja Nau ${ }^{2}$, Harald F Krug ${ }^{3}$, Björn Mathes ${ }^{4}$ and Christoph Steinbach ${ }^{4}$
}

\begin{abstract}
Background: Assessing the impact of new technologies or newly developed substances on our environment is a challenge, even more so if the applied test methods - both toxicological and analytical - are often found to be inadequate and need amendments or even new developments as it is in the case of nanotechnology. This is illustrated by numerous publications in the field of nano-ecotoxicology which although they have been investigating the impact of a number of nanomaterials on several organisms almost never allow for explicit statements on potential hazards of these nanomaterials. This fact not only hampers the knowledge communication to all non-scientists (e.g. consumers) but it also complicates the transfer of the obtained results for other scientists.
\end{abstract}

Results: Risk communication is an essential and thus integral part of risk management. For this purpose, the project DaNa2.0 (Data and knowledge on nanomaterials - processing of socially relevant scientific facts) provides processed and hence easy accessible information on the potential safety issues of nanomaterials, mainly via the project website www.nanoobjects.info. This will allow various stakeholder groups to get impartial information on potential effects of nanomaterials and help consumers to make informed decisions. DaNa2.0 is funded by the German Federal Ministry of Education and Research (BMBF) and supported by the Swiss government as well as by the European InterReg IVb programme. The DaNa2.0 team is an interdisciplinary group of scientists from different areas such as materials science, chemistry, biology and human and environmental toxicology. Extending the project team in DaNa2.0 with European experts allows for broadening of the existing knowledge portfolio by adding further cross-cutting topics and increasing our expertise, e.g. in the field of environmental exposure and fate.

Conclusions: On the project website www.nanoobjects.info, a unique link between nanomaterials in practical applications (e.g. environmental remediation) and their potential impacts is provided. The focus of this publication will be on all issues with environmental relevance, which are addressed in the 'Knowledge Base Nanomaterials' on the project website. These issues include environmental exposure and behaviour of nanomaterials and nano-ecotoxicology.

Keywords: Nanomaterials; Nano-objects; Nano-ecotoxicity; Knowledge base; Knowledge dissemination; Nanotechnology; Environmental impact

\section{Background}

Since the start of the DaNa project with its corresponding website www.nanoobjects.info in 2009 and its continuation in DaNa2.0 since 2013, the annual number of publications dealing with toxicological aspects of nanomaterials has been increasing exponentially. Numerous research papers on various nanomaterials and organisms

\footnotetext{
* Correspondence: dana.kuehnel@ufz.de

1 Department of Bioanalytical Ecotoxicology, Helmholtz Centre for Environmental Research - UFZ, 04318 Leipzig, Germany

Full list of author information is available at the end of the article
}

have been published (as demonstrated by extensive reviews, e.g. [1,2]), resulting in a growing number of nanomaterials (NM) and their related information on the website. Besides the scientific output of these literature sources, there is an increasing demand for more information on this new technology, reflected in the growing number of visitors to the project website.

However, it is still difficult to provide simple and explicit statements on potential environmental hazards of nanomaterials. This is either due to a lack of information, e.g. regarding the physico-chemical properties of nanomaterials, 
or due to a high variation in test procedures and consequently to a high variability in test results. Beyond that, the transfer of nano-toxicity-related information to scientist from other fields and also to non-scientists is difficult. To bridge this gap, the project $\mathrm{DaNa} 2.0$ is working on improving these communication pathways from nanosafety-related science to various stakeholder groups. The major goal of the DaNa Knowledge Base Nanomaterials is to provide condensed, up-to-date and easy comprehensible information on the safety of nanomaterials for different recipient groups simultaneously [3-5]. The website provides a unique combination of material science-based information and nano-applications with toxicological information, helping, e.g. consumers in making informed decisions.

In order to assess the quality of the published studies and to consequently achieve an aggregation to the ones meeting the requirements of good scientific practice, the $\mathrm{DaNa}$ expert team developed the so-called Literature Criteria Checklist. The list of chosen criteria allows the side-by-side evaluation of background information on the applied nanomaterial together with the selected toxicological assays [4]. Ultimately, only those scientific findings complying with the checklist will be integrated in the knowledge base. This evaluation process along with the writing of the respective articles is achieved by a multidisciplinary core team that is supported since the start of the follow-up project DaNa2.0 (2013) by several external experts bringing in their expertise in specific fields.

In order to cover the full scope of potential interactions of nano-related applications with the various organisms, the DaNa2.0 expert team evaluates all scientific research papers with regard to human and ecotoxicological aspects thereby continuously updating the articles on the 25 market-relevant nanomaterials listed on the website [3].

This paper focuses on the DaNa2.0 activities with regard to environmental aspects, namely exposure and behaviour in the environment, as well as potential hazards towards environmental organisms. Furthermore, the website provides an overview of the German Nanosafety Research Landscape. On the DaNa2.0 internet platform, research projects funded by the German Federal Ministry of Education and Research (BMBF) are provided with the opportunity to present their project results related to environmental issues of nanotechnology in a recipient-friendly way.

\section{Results and discussion}

DaNa2.0 - general structure of the platform (www.nanoobjects.info)

The content of the website is structured into different areas providing different types of information on the opportunities and potential risks of nanotechnology:
1. Knowledge base - provides comprehensive articles on application, material properties, exposure, behaviour and toxicity of currently 25 engineered nanomaterials (ENMs)

2. Basics - provides short information on basic issues from release to uptake behaviour, risk and fate of ENM

3. Cross-cutting section - provides comprehensive articles on over-arching issues in nanotechnology, significant to more than one ENM

4. Methodology - provides a collection of nano-relevant standard operating procedures (SOPs) (template and finalised documents) together with documents used for quality management of cited literature (Literature Criteria Checklist)

5. Projects section - provides an overview on relevant funded national projects

6. Frequently asked questions (FAQ) section - provides a collection of questions and answers to relevant nano-related issues and opportunity to directly ask questions to the DaNa2.0 experts

7. Glossary - provides short definitions of related terms used in the articles

8. News section - provides announcements of new developments in nanotechnology, important publications, conferences and workshops, and more

9. Links section - provides links to websites, networks, information platforms as well as national and international projects on nanotechnology and safety issues

The content of the articles within the knowledge base and also in the cross-cutting section is presented in three levels of complexity according to needs and interest of different recipient groups:

1. Short and basic - interested citizens/consumers (public oriented)

2. Detailed - journalists, stakeholders, scientists from other fields

3. Complex - scientists from related fields, regulators

\section{DaNa2.0 Knowledge Base Nanomaterials}

The core section of the DaNa2.0 web platform is the knowledge base which provides a wealth of facts and data for currently 25 market-relevant nanomaterials. The actual state of knowledge is derived from evaluation of the scientific literature, from project reports and official reports from governmental agencies or organisations. An application-based database was established, as most visitors rather seek information related to a specific product than to a specific type of nanomaterial (Figure 1). The table-based approach allows the selection either of an application, e.g. 'environmental remediation' and 


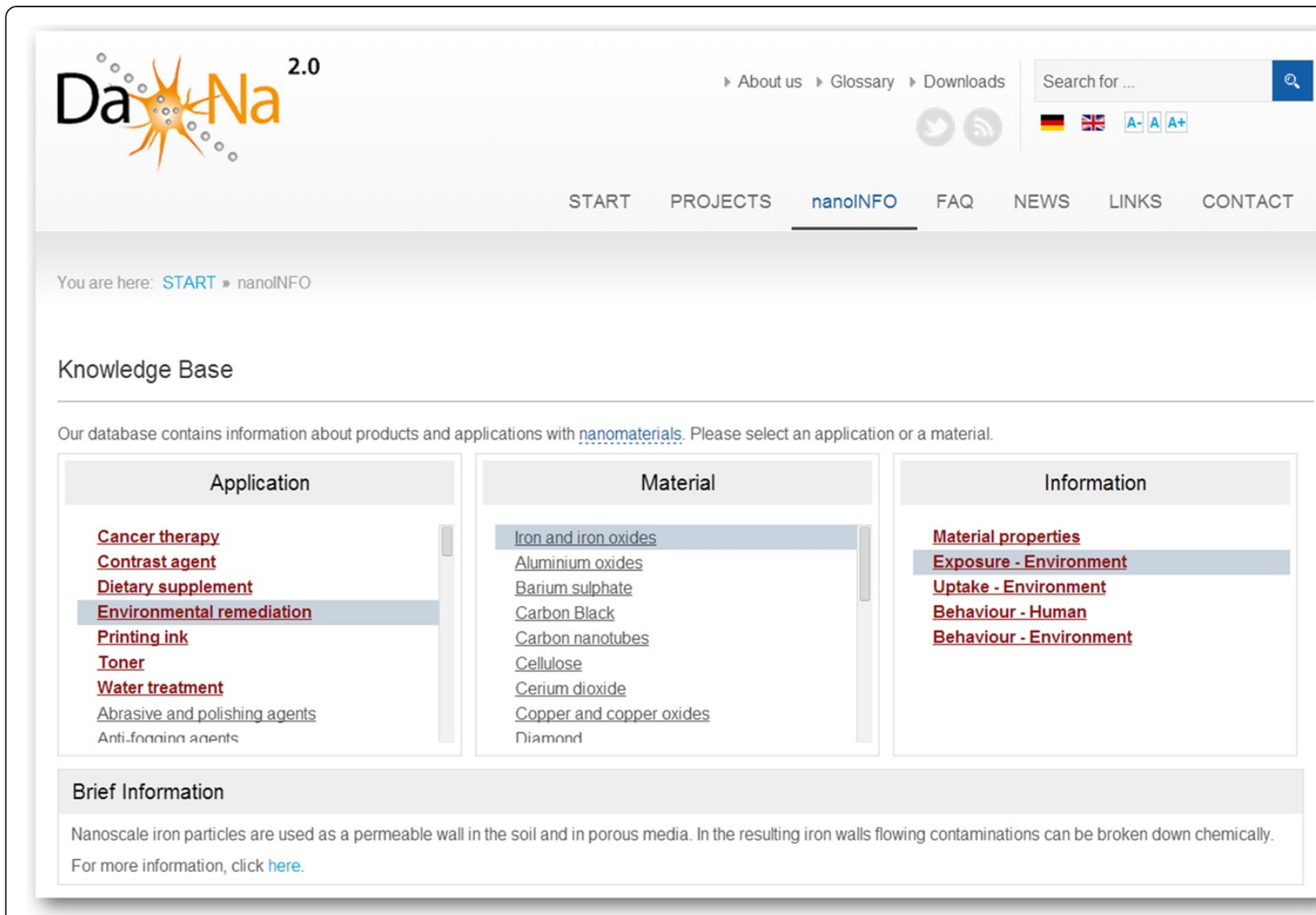

Figure 1 Knowledge base. The knowledge base is the core of the DaNa2.0 website and is organised in a table-based approach to provide links between nanomaterials, nano-products, and additional information on the material and potential toxicological effects [6].

'textiles' (Figure 1, column 1), or of an ENM of interest, e.g. 'iron oxide' (Figure 1, column 2). In turn, the nanomaterial used in the respective type of application or the type of application belonging to an ENM is highlighted. Several applications with an environmental background are already included and the total list of applications which is updated on a regular basis. Having selected the desired application together with a material, the availability of further information on exposure, uptake, behaviour and the material is indicated (Figure 1, column 3). By selecting an issue of interest, the brief information box below the table not only provides a comprehensive statement on the state of knowledge but also allows accessing more complex information. The interested visitor is then navigated to the more in-depth content of the main knowledge base. Likewise, all 25 ENMs included in the knowledge base can also be accessed directly via the material menu.

The in-depth content of the knowledge base provides besides general material information (production, usage, properties) sections on exposure, uptake and behaviour with regard to human and environmental toxicology and potential risks for environmental organisms (e.g. fish, plants, mussels; see Table 1). Figure 2 shows an exemplary excerpt from the website for the nanomaterials 'iron and iron oxides' that deals with 'uptake and potential risks for environmental organisms'. The introduction of organism icons is currently introduced into the articles to facilitate the navigation and information access.

An overview on the huge variety of organisms, primary cells and cell lines used to study potential hazardous effects of nanomaterials is given in Table 1, summarising the 25 market-relevant ENMs currently listed in the knowledge base together with the corresponding environmental test systems. For 23 out of the 25 listed ENMs in the knowledge base, there is ecotoxicological information available. As for the human toxicology, the body of literature on environmental effects of nanomaterials is growing rapidly resulting in the aforementioned problems with comparability. In most cases, different types of the same nanomaterials were used or experimental conditions varied from study to study making it increasingly difficult to interpret and compare the results [9]. In order to deal with these issues, the DaNa expert team developed the 'Literature Criteria Checklist' to manage and monitor the quality 
Table 1 Overview of all 25 market-relevant nanomaterials listed currently in the DaNa knowledge base

\begin{tabular}{|c|c|c|c|}
\hline Nanomaterial & $\begin{array}{l}\text { Environmentally relevant application or product } \\
\text { with likely release to the environment }\end{array}$ & $\begin{array}{l}\text { Anticipated most relevant release } \\
\text { path/way }\end{array}$ & $\begin{array}{l}\text { Studied organisms/cells/cell lines considered in the knowledge } \\
\text { base at www.nanoobjects.info }\end{array}$ \\
\hline Aluminium oxide & Abrasive and polishing agents & Aerosols & $\begin{array}{l}\text { Mud tube worm, shrimp, earthworm, basket shell, nematode, bacteria, } \\
\text { daphnids, zebrafish, thale cress, rye, lettuce, corn, carrots, soy, cabbage, } \\
\text { cucumber, radish, rapeseed, ryegrass }\end{array}$ \\
\hline Barium sulphate & Contrast agent & Waste water & No ecotoxicity studies available \\
\hline Carbon black & Printing ink, toner & Aerosol & Common mussel, brown algae (toothed wrack), fruit fly, amphipods \\
\hline Carbon nanotubes (CNT) & $\begin{array}{l}\text { All applications anticipated so } \\
\text { far involve CNT embedded } \\
\text { in a matrix }\end{array}$ & & $\begin{array}{l}\text { Rainbow trout, earthworm, lugworm, tomato, cabbage, carrot, onion, } \\
\text { radish, rape, lettuce, ryegrass, corn and cucumber }\end{array}$ \\
\hline Cellulose & Wound dressing & Solid waste & Bacteria, fungi, daphnids, fish, algae, rainbow trout liver cells \\
\hline Cerium dioxide & Diesel additive & Car exhaust & $\begin{array}{l}\text { Bacteria, algae, zebrafish (embryo, adult), daphnids, rainbow trout } \\
\text { liver cells, soybean }\end{array}$ \\
\hline $\begin{array}{l}\text { Copper and copper } \\
\text { oxide }\end{array}$ & Wood preservatives & Waste & $\begin{array}{l}\text { Bacteria, protozoa, worms, snail, frog embryo, zebrafish, green algae, } \\
\text { radish, ryegrass, duckweed, corn }\end{array}$ \\
\hline Diamond & Abrasive and polishing agents & Aerosol & Nematodes, frog embryos, daphnids \\
\hline Fullerenes & $\begin{array}{l}\text { Cosmetics, sports equipment, } \\
\text { lubricant }\end{array}$ & Direct release to surface or waste water & $\begin{array}{l}\text { Bacteria, algae, daphnids, common mussel blood cells, oyster (larvae, } \\
\text { adult, liver cells), zebrafish embryo }\end{array}$ \\
\hline Gold & Diagnostics and therapy & Waste water & $\begin{array}{l}\text { Bacteria, daphnids, blue mussel, basket shell, zebrafish embryo, rainbow } \\
\text { trout liver cell, cucumber, lettuce }\end{array}$ \\
\hline Graphene & No applications on the market, yet & & Bacteria, nematodes, zebrafish embryo, tomato, spinach, cabbage \\
\hline Indium tin oxide (ITO) & $\begin{array}{l}\text { All applications anticipated so far } \\
\text { involve ITO embedded in a matrix }\end{array}$ & & Various aquatic organisms (vertebrates, algae) \\
\hline Iron and iron oxides & Ground and waste water remediation & Intended release to ground water & $\begin{array}{l}\text { Bacteria, medaka embryos, rainbow trout gill cells, pumpkin, lima bean, } \\
\text { ryegrass }\end{array}$ \\
\hline Platinum & Catalytic exhaust converter & Aerosol formation & Zebrafish embryo, rainbow trout gill cells \\
\hline Quantum dots (QD) & $\begin{array}{l}\text { All applications anticipated so } \\
\text { far involve quantum dots } \\
\text { embedded in a matrix }\end{array}$ & & Bacteria, algae, daphnids, zebrafish embryo, rainbow trout \\
\hline Silicon dioxide & Skin care, textiles, therapeutics & Surface and waste water & Bacteria, green algae, mussel blood cells \\
\hline Silver & Textiles, antimicrobial applications & $\begin{array}{l}\text { Wash-off, release of ions from silver-coated } \\
\text { surfaces }\end{array}$ & $\begin{array}{l}\text { Bacteria, fungi, green algae, daphnids, zebrafish embryo, medaka } \\
\text { cell line }\end{array}$ \\
\hline Strontium carbonate & Pyrotechniques & Aerosol & No ecotoxicity studies available \\
\hline Titanium dioxide & Sunscreen, surface coating & $\begin{array}{l}\text { Direct release to surface waters, run-off from } \\
\text { coated surfaces }\end{array}$ & $\begin{array}{l}\text { Bacteria, daphnids, nematodes, lugworm, mussel, snail, woodlice, } \\
\text { rainbow trout, zebrafish (embryo and adult), green algae, onion, } \\
\text { willow, tobacco }\end{array}$ \\
\hline Titanium nitride & $\begin{array}{l}\text { All applications anticipated so far } \\
\text { involve TiN embedded in a matrix }\end{array}$ & & Rainbow trout gill and intestinal cells \\
\hline
\end{tabular}


Table 1 Overview of all 25 market-relevant nanomaterials listed currently in the DaNa knowledge base (Continued)

Tungsten carbide (WC) WC nanoparticles are used for tool

production and are tightly bound in

the tools

Tungsten carbide cobalt WC-Co nanoparticles are used for tool

(WC-Co) production and are tightly bound in

the tools

Zeolite/clays Fertiliser

Zinc oxide Sunscreen, textiles

Zirconium dioxide

All applications anticipated so far involve $\mathrm{ZrO}_{2}$ embedded in a matrix

Relevant environmental applications, the anticipated most relevant release path into the environment and the test organisms used in the studies were considered in this summary. As the whole ENM life cycle was not

considered, disposal as relevant release at end of life was left out.

Soil

Direct release to surface waters, wash-off
No ecotoxicity studies available

Bacteria, protozoa, woodlice, zebrafish, rainbow trout, daphnids, green algae, ryegrass, corn, soybean, zucchini, thale cress

Bacteria, algae, zebrafish embryo 


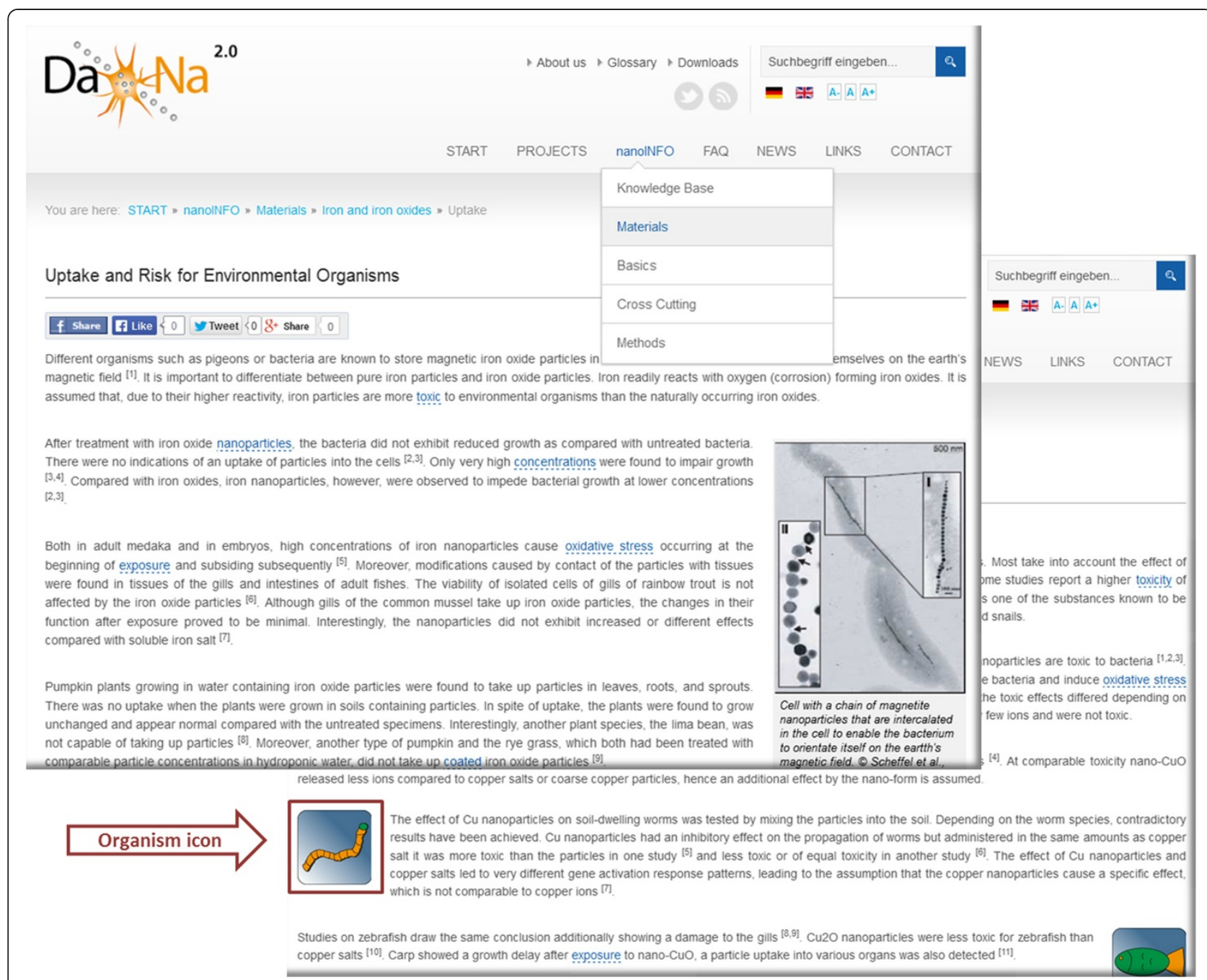

Figure 2 DaNa2.0 knowledge base. The DaNa2.0 knowledge base provides a constantly growing source of information regarding the environmental impact of nanomaterials [7]. For 23 out of the 25 nanomaterials included in the knowledge base, there is ecotoxicological information available. Currently, the accessibility of information is improved by using organism icons to facilitate the navigation throughout the articles [8].

of all used literature prior to inclusion and publication in the knowledge base (see respective chapter).

In general, consumer products with a high likelihood of the applied ENM to get in close contact to the user such as sunscreen or textiles are of biggest concern for humans whilst at the same time these ENMs are also the most prone to enter our environment. Therefore, these ENMs have also a great potential to be hazardous for the environment and its inhabitants, and ultimately, a polluted environment will always act back on humans and their conditions of living. Keeping this in mind, the DaNa2.0 team supported by the external experts is working continuously on constantly updating the state of knowledge in these fields. Specifically for environmental issues, the external experts provide background in (environmental) risk assessment, ecotoxicity, NM release and transport, and exposure assessment.

\section{Other sections with environmental relevance Basics section}

The basics section provides fundamental introductions into nanotechnology and safety issues, such as general information on release of nanomaterials, uptake and behaviour in organisms and environmental media, as well as a section on how to assess the potential risk NM pose to humans and the environment (Figure 3).

\section{Cross-cutting section}

This section deals with overarching issues with significance to ENMs in general. The two articles currently published on the website deal with coatings and with different crystal structures of ENM, respectively. Both issues are not only of relevance to materials scientists but also need consideration in (eco)toxicological testing. This section will be further expanded during the term of 


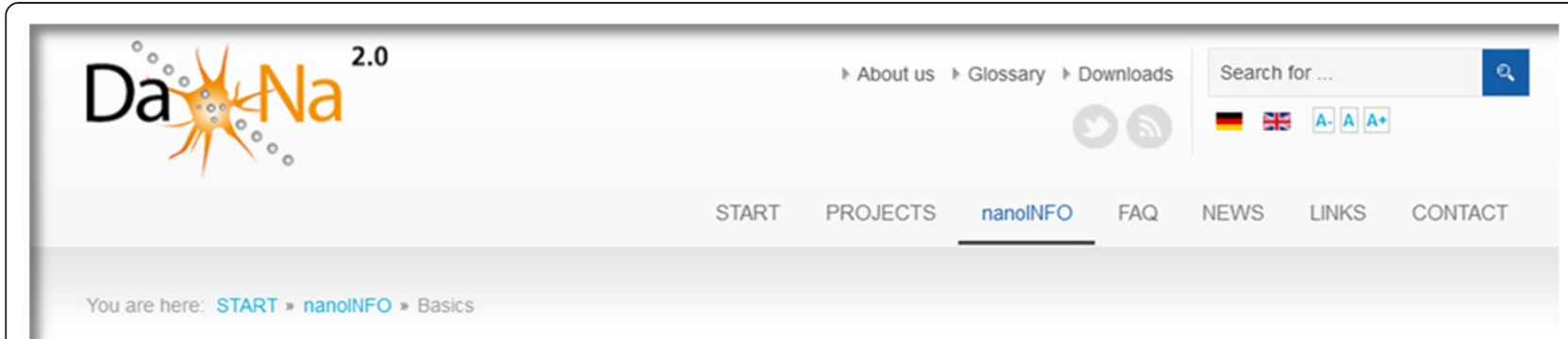

General Information on Nanomaterials

The discovery or development of novel chemicals or materials creates a demand of new knowledge as regards the related potential biological effects and health hazards. Before such materials are launched for different uses, they must be tested for safety without any risks to health according to the legal requirements in the different countries. In Germany these are for example the chemicals ordinance, the medicinals products act, the food regulations, the cosmetics and detergents ordinances, and various other regulations. These requirements are also valid for and applied to

$$
\text { Read more. }
$$

How do you get in contact with nanomaterials?

Certain nanomaterials are expected to conquer future markets due to their outstanding properties. The considerable increase in production and the increased use of products that contain materials like that may result in a higher exposure of humans and of the environment. For humans, this may be of relevance to workplaces during production and may play a role when such materials are used or are disposed of. Protective measures or preventive examinations are always part of occupational health and safety and of product safety measures. A release of engineered nanoparticles into the...

Read more.
How are nanomaterials released?

An exposure to nanoparticles of people and the environment with possible incorporation and impacts can only occur when nanoparticles are released. Consequently nanoparticles cause no effects when they are not released. Nevertheless, during the life time of nanomaterials nanoparticles can be set free by various processes during e. g. production, application or after use. Nanoparticles which are embedded in a composite material can be released into the environment by mechanical, thermal or chemical processes, see figure 1. Mechanical processes can be e. g. drilling, grinding and sawing...

Read more.
How can nanomaterials enter the body or the environment?
The biological effect of materials or substances depends on their ability of reaching the body or rather the organs and cells inside the body. Detection of the uptake in the respective organism is an essential factor in evaluating nanomaterials and nanoparticles. Like in the case of other substances, nanomaterials are taken up depending on how they occur in the environment: as free particles, bound in another substance e.g., as reinforcements in plastics; distributed in a liquid e.g., as constituents of lubricants or oils. Basically, there are three pathways for all substances.

Read more.

Figure 3 The basics section. It gives an overview on fundamental questions related to the safety of engineered nanomaterials [10].

the project by, e.g. including articles on ENMs in paints or on ENM detection in the environment.

\section{Projects and standard operating procedures}

Besides the knowledge base, another main focus of DaNa2.0 is to give an overview of the German Nanosafety Research Landscape including previous, current and future nano-(eco)toxicology-related projects funded by the BMBF. Twelve projects were part of the funding action NanoNature (running from 2009 to 2014), referring mostly to environmental applications. The projects conducted research on, e.g. the improvement of catalytic processes or filtration techniques by applying nanotechnology. Some projects also covered the assessment of potential ecotoxicological hazards of the nanomaterials investigated (e.g. Fe-Nanosit). Three projects dealt with iron-based nanoparticles or nanocomposites applied in environmental remediation, specifically the decontamination of ground water (e.g. Fe-Nanosit, see Figure 4). Most of the funded projects have been completed until early 2014. Hence, future tasks for the DaNa2.0 team are to first display these results (reports, publications, etc.) on the respective project pages and next to implement these new findings, if having met the necessary quality criteria to enter into the knowledge base (Figure 2). Furthermore, SOPs developed within the projects will be published via the website. New projects will start soon and will be likewise presented.

Additionally, the DaNa2.0 team supported the exchange and interaction between projects from the funding initiatives NanoCare and NanoNature with annual cluster meetings which are planned to continue once the new projects have started. One successful outcome of these cluster meetings was the creation of an interest group 


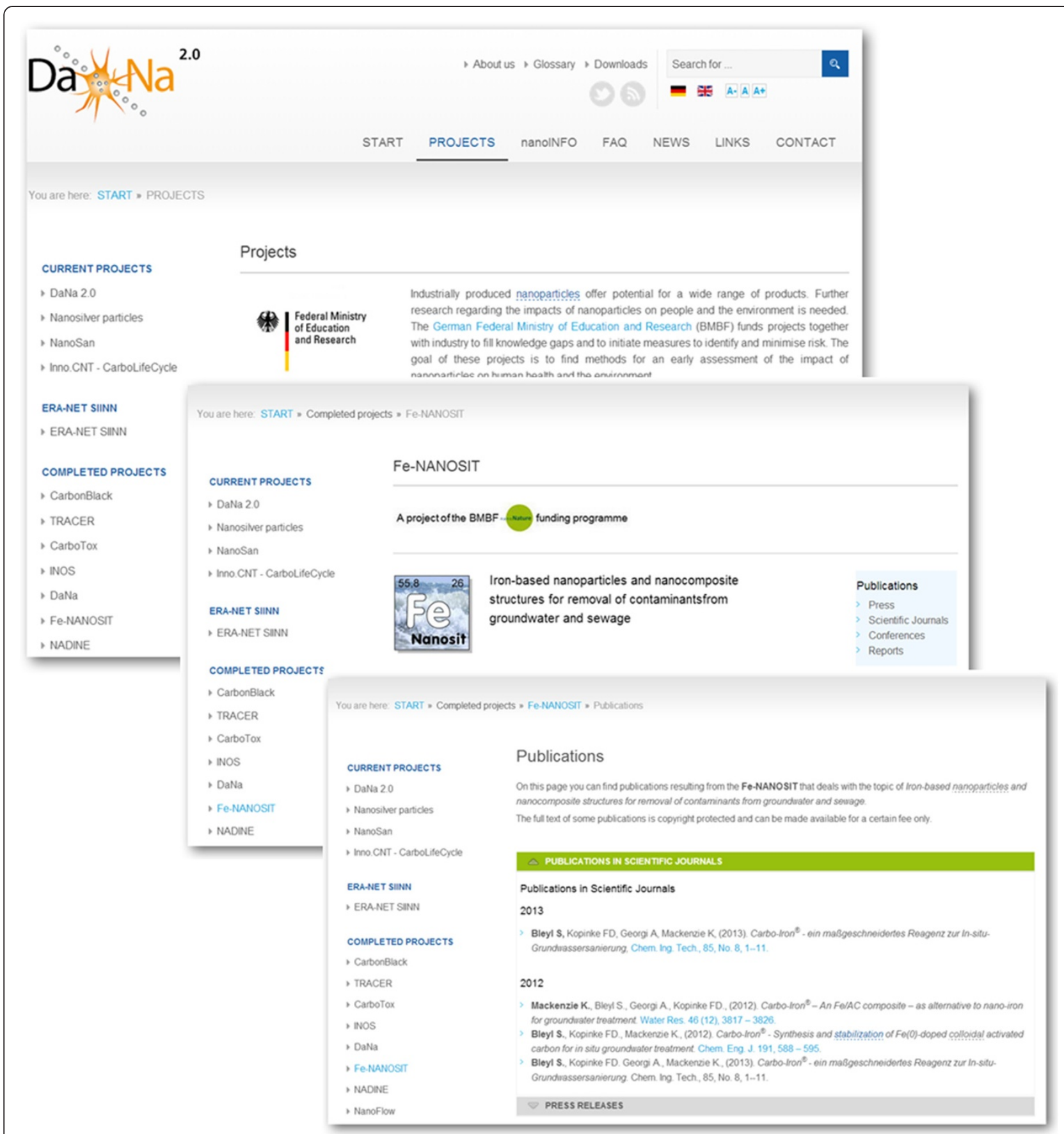

Figure 4 The projects section. It gives an overview on the German Nanosafety Research Landscape and presents all relevant projects within the funding actions NanoCare and NanoNature [11]. Most projects have been completed by early 2014, and the inclusion of results is currently under way. On the individual project sites - here shown for the project Fe-Nanosit - the main scope of each project is presented, together with all project partners, and major outcomes (reports, publication) are listed and linked to the respective sources [12,13].

of ecotoxicologists focussing on the specific peculiarities of iron-based nanomaterials that need to be considered in ecotoxicity testing. This interest group for example organised a workshop focusing on physicochemical characterisation of these nanomaterials before conducting ecotoxicological tests.
Accounting for the need to harmonise experimental practices, the DaNa2.0 team in close cooperation with project members from the nano-funding initiatives developed a template for SOPs. The aim was to provide a common format to share, compare and describe methodologies specific to nanomaterials. But the template 
may also be used by other projects or serve as a basis for future projects and publications. The pdf form is available for download via the website [14].

\section{Frequently asked questions}

The Frequently asked questions (FAQ) section gives answers to the most common and important questions on nanomaterials and nanotechnology. These include questions specifically relating to environmental issues, e.g. How are nanoparticles displayed in the context of recycling management? How can I recognize whether a product contains nanoparticles? How dangerous are nanoscale particles that are already present in the environment? There is also the possibility to directly interact with the DaNa2.0 experts by submitting questions related to nanomaterials via email. The DaNa2.0 team will respond and publish the answer on the website if considered to be of public relevance.

\section{Glossary}

In some instances, the usage of terms very specific to nanotechnology and related fields is hard to avoid. In order to provide further explanation, the glossary not only gives quick and easy definitions for general terms like 'zeta potential', 'agglomerate' or 'surface charge' but also covers terms from environmental sciences, such as 'bioaccumulation' or 'predicted environmental concentration'. It is assessable either directly in alphabetic order or via tooltip by choosing the marked terms in the text (see Figure 5 ).

\section{Literature criteria checklist}

The need to develop the DaNa Literature Criteria Checklist arose from the necessity to manage the evaluation of all nano-toxicity data regarding its scientific value prior to including it in the knowledge base. In this way, all data with insufficient background information on the investigated ENMs or on the applied methodology will be excluded from the knowledge base, as these data will lead to false conclusions on potential toxic effects of nanomaterials. The assessment criteria cover (1) the extent of the physical-chemical characterisation of the ENMs, (2) the toxicity testing procedures and (3) general issues (e.g. data evaluation). In addition, mandatory assessment criteria are specified, in distinction to desirable criteria. The complete list of quality criteria is accessible to all interested scientists via the DaNa2.0 website [17]. Evaluating every scientific publication according to the criteria finally allows for selection of solely those papers that provide sound

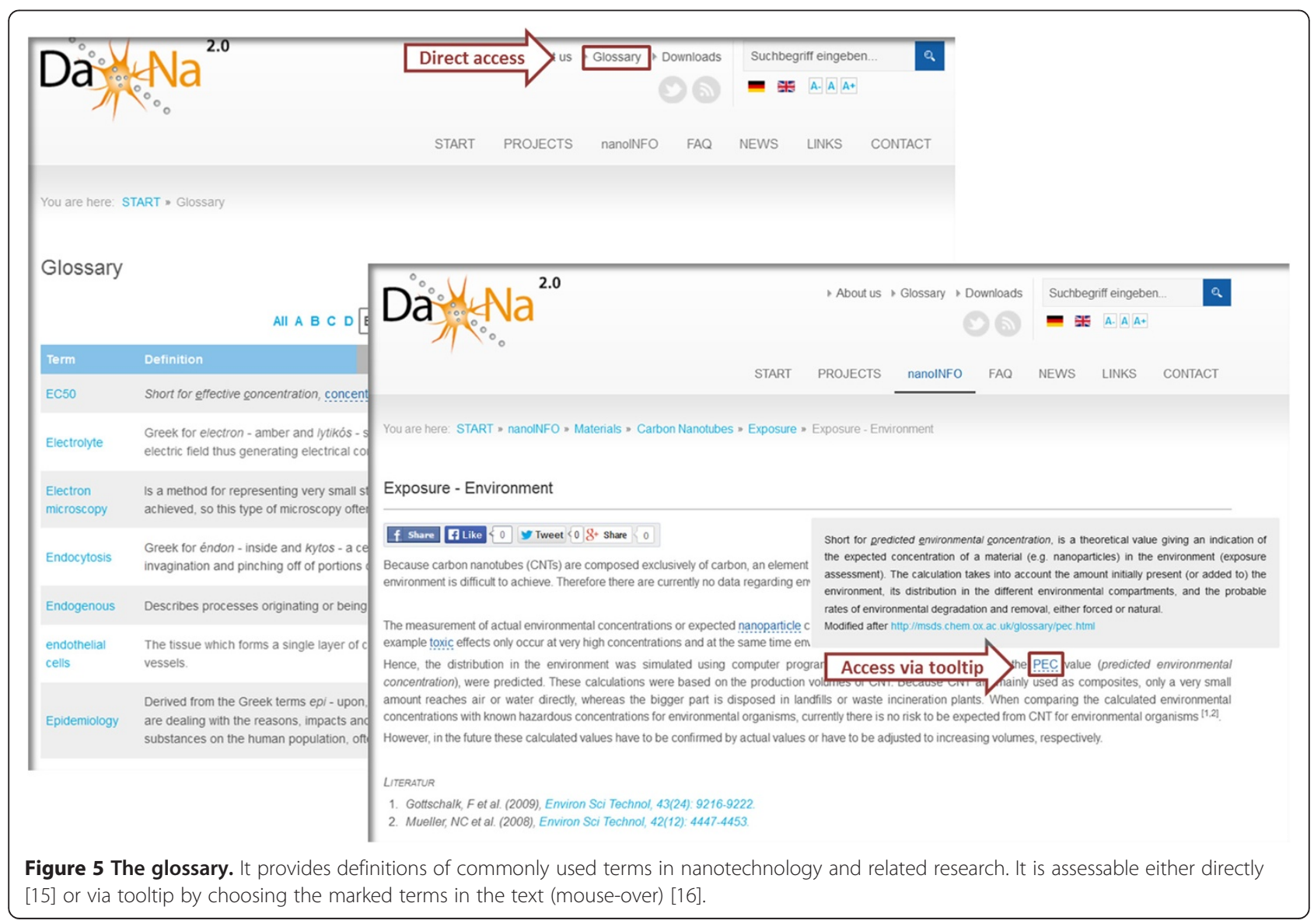


background information on the nanomaterials and the toxicological tests applied [4]. Hence, only scientific facts complying with the checklist will be included in the knowledge base.

\section{Dissemination of nanotechnology-related information}

The main aim of the teams' dissemination activities is to provide the general public with sound and up-to-date information related to nanotechnology. The most important instrument for this task is the website www.nanoobjects. info. Since the launch of the website in 2009, a constant increase in the visitor numbers was observed, demonstrating a high need for information (Figure 6). The statistical data shown in Figure 6 clearly demonstrate that not only the overall visitor numbers are increasing but also there is a growing international awareness level for a national project. Amongst the top 10 visitor countries, the USA and China come in second and third place, respectively, after Germany but ahead of other European countries such as the UK or Switzerland. Besides the DaNa2.0 website, the expert team uses additional channels to communicate the collected knowledge on nanotechnology-related issues to interested laymen. Members of the DaNa2.0 team participate regularly in group discussions, public dialogue events, conferences (e.g. SETAC) and fairs, and interact with journalists (interviews, commentaries, etc.). Beyond that, the annual cluster meetings, the place where partners of the

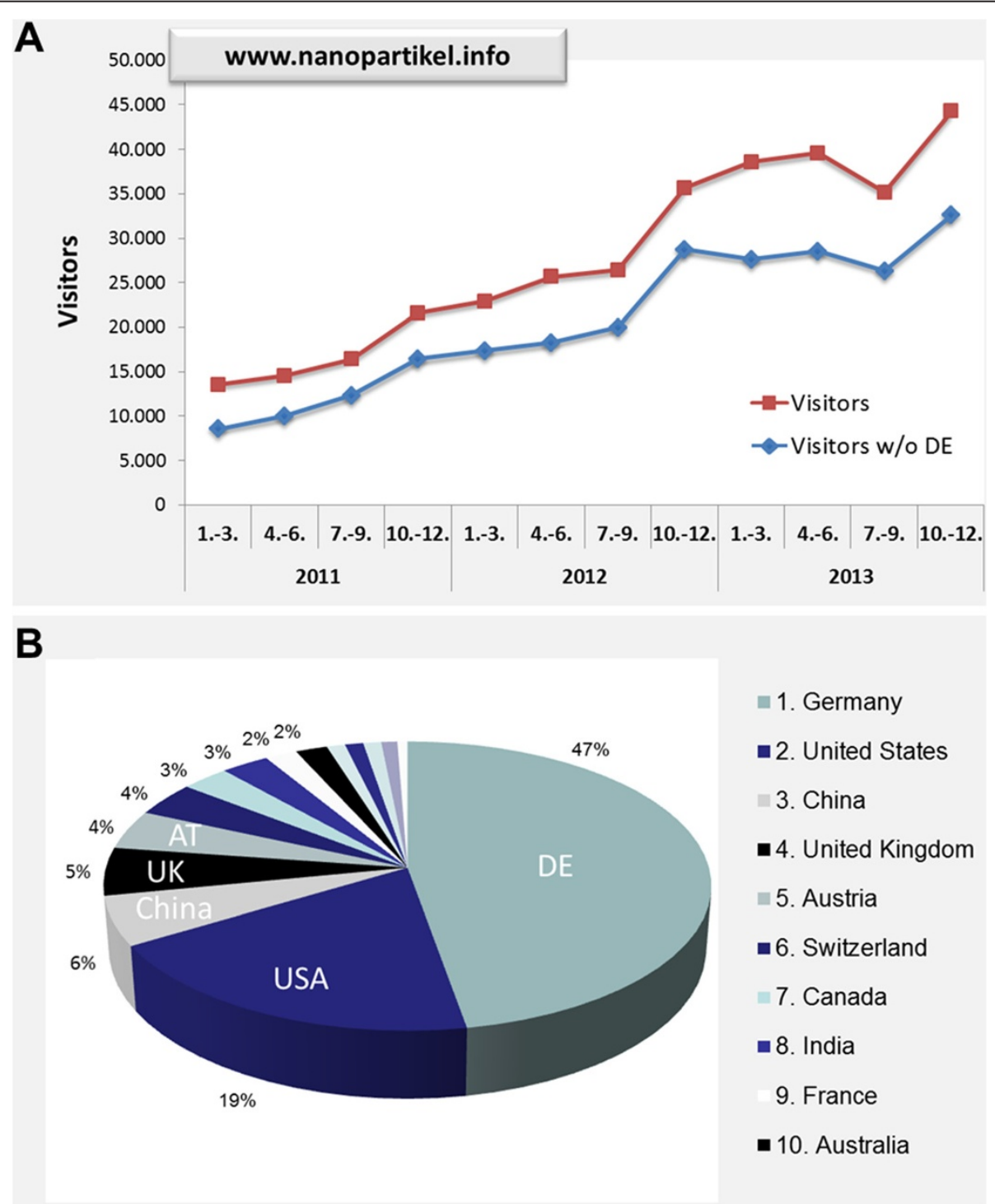

Figure 6 Access statistics from the website. Increasing national and international demand for sound and up-to-date information on nanotechnology. (A) Visitor numbers from 2011 to 2013 summarised quarterly in total (red) and without Germany (blue). (B) Top 10 visitor countries from 2013. 
BMBF-funded projects are given the opportunity to exchange and interact, are also partly open to the public.

\section{Conclusions}

The DaNa2.0 website offers easy access to complex scientific issues related to the environmental impact of nanomaterials. The information provided is constantly extended, updated and adjusted to the latest developments in the field of nanotechnology. Taking into account the rapid development in the field of nanotechnology, keeping all the content of www.nanoobjects.info constantly updated is a challenge. Hence, the involvement of European environmental experts in the DaNa2.0 consortium will not only provide further input by, e.g. including further issues with environmental relevance, such as risk assessment and realistic environmental exposure, but will also facilitate the inclusion of latest research results. Likewise, the 'entry port' for scientific facts to be integrated into the knowledge base, the Literature Criteria Checklist, is currently being critically revised. With regard to ecotoxicity testing, specific criteria to, e.g. evaluate the application of nanomaterials to the test media (e.g. soil) and also concerning analytic methods have to be developed and included.

The DaNa2.0 consortium will further strengthen the cooperation and exchange with other dissemination organisations (databases, websites, projects) on the national and international level. Examples are the associations to EU projects such as eNanoMapper (www.enanomapper.net), NanoValid (www.nanovalid.eu) and the InterRegIVbfunded project NANORA (www.nanora.eu), the latter is initiating a French version of the knowledge base. International contributions include also the dialogue with the European NanoSafetyCluster and contributions to an international activity concerning curation of nanotechnology data coordinated by the US NCIP Nanotechnology Working Group [18]. Additionally, members of the DaNa2.0 team participate in several public dialogues or discussions on nanotechnology and nano-toxicology in order to inform the public and raise awareness for their activities. The team is also contributing to other international activities such as the OECD WPMN activities [19]. Citations of the DaNa2.0 website as single national database in the European Commission's 'Commission Staff Working Paper' [20], in 'The JRC Web Platform on Nanomaterials' [21] and in the commentary 'Focusing the research efforts' [22] clearly demonstrate the importance and quality of the provided data, respectively. Finally, the comprehensive collection of environmental relevant facts on nanomaterials will assist in defining knowledge gaps and further research needs.

\section{Methods}

This article describes how information of nanotechnology and its potential adverse effects are collected, evaluated and edited in order to provide generally understandable facts and information on a web-based platform. A more detailed description of the methodology applied can be retrieved from the paragraphs introducing the single sections of the website.

\section{Abbreviations \\ BMBF: German Federal Ministry of Education and Research; DaNa2.0: Data and knowledge on nanomaterials - evaluation of socially relevant scientific facts; ENM: engineered nanomaterial; JRC: Joint Research Centre; NM: nanomaterials; OECD: Organisation for Economic Co-operation and Development; WPMN: Working Party on Manufactured Nanomaterials; SETAC: Society of Environmental Toxicology and Chemistry; SOP: standard operating procedures.}

\section{Competing interests}

The authors of this article form the core team of DaNa2.0. The core team and the external experts are funded by the German Federal Ministry for Education and Research (BMBF) under grant no. 03X0131. They are also the authors of the content published on the project website www.nanoobjects.info.

\section{Authors' contributions}

DK and CM drafted and revised the manuscript. KN included information regarding the website and access statistics. BM and CS provided input regarding materials science and cooperation and synergisms to other projects. HK and CS included information on cooperation and synergisms to other projects. All authors read and approved the final manuscript.

\section{Acknowledgements}

We thank the German Federal Ministry for Education and Research (BMBF) for funding the DaNa2.0 project (Data and knowledge on nanomaterials evaluation of socially relevant scientific facts), grant no. 03X0131 (August 2013 to July 2017)

\section{Author details}

${ }^{1}$ Department of Bioanalytical Ecotoxicology, Helmholtz Centre for Environmental Research - UFZ, 04318 Leipzig, Germany. ${ }^{2}$ Institute for Applied Computer Science, Karlsruhe Institute of Technology (KIT), 76344 Eggenstein-Leopoldshafen, Germany. ${ }^{3}$ Research Focus Area Health and Performance, Empa - Swiss Federal Laboratories for Materials Science and Technology, 9014 St. Gallen, Switzerland. ${ }^{4}$ Society for Chemical Engineering and Biotechnology (DECHEMA), 60486 Frankfurt am Main, Germany.

Received: 4 April 2014 Accepted: 1 August 2014

Published online: 02 October 2014

\section{References}

1. Bondarenko O, Juganson K, Ivask A, Kasemets K, Mortimer M, Kahru A: Toxicity of $\mathrm{Ag}, \mathrm{CuO}$ and $\mathrm{ZnO}$ nanoparticles to selected environmentally relevant test organisms and mammalian cells in vitro: a critical review. Arch Toxicol 2013, 87(7):1181-1200.

2. Jackson P, Jacobsen NR, Baun A, Birkedal R, Kuhnel D, Jensen KA, Vogel U, Wallin $\mathrm{H}$ : Bioaccumulation and ecotoxicity of carbon nanotubes. Chem Cent J 2013, 7.

3. Steinbach C, Mathes B, Krug HF, Wick P, Kühnel D, Nau K: Die Sicherheit von Nanomaterialien in der Diskussion: DaNa, eine InternetWissensplattform für Interessierte. Deutsche Apotheker Zeitschrift 2012, 152(16):90-92.

4. Marquardt C, Kühnel D, Richter V, Krug HF, Mathes B, Steinbach C, Nau K: Latest research results on the effects of nanomaterials on humans and the environment: DaNa - Knowledge Base Nanomaterials. J Phys Conf Ser 2013, 429:012060.

5. Krug HF, Wick P, Hirsch C, Kühnel D, Marquardt C, Nau K, Mathes B, Steinbach C: Im Gleichgewicht? Risikoforschung zu Nanomaterialien. Arbeitsmed Sozialmed Umweltmed 2014, 49:6-18.

6. The DaNa2.0 Knowledge Base. [http://www.nanopartikel.info/en/nanoinfo/ knowledge-base]

7. Uptake and risk for environmental organisms (iron and iron oxides). [http://www.nanopartikel.info/en/nanoinfo/materials/iron-and-iron-oxides/ uptake/1351-uptake-and-risk-for-environmental-organisms] 
8. Uptake and risk for environmental organisms (copper and copper oxides). [http://www.nanopartikel.info/en/nanoinfo/materials/copper-andcopper-oxides/uptake/1413-uptake-and-risk-for-environmental-organisms]

9. Hansen S, Jensen K, Baun A: NanoRiskCat: a conceptual tool for categorization and communication of exposure potentials and hazards of nanomaterials in consumer products. J Nanopart Res 2013, 16(1):1-25.

10. Basics section. [http://www.nanopartikel.info/en/nanoinfo/basics]

11. Projects section. [http://www.nanopartikel.info/en/projects]

12. Projects (Fe-Nanosit). [http://www.nanopartikel.info/en/projects/completedprojects/fenanosit]

13. Project (Fe-Nanosit) publications. [http://www.nanopartikel.info/en/ projects/completed-projects/fenanosit/ver-fe-nanosit]

14. SOPs section. [http://www.nanopartikel.info/en/nanoinfo/methods/992standard-operating-procedures]

15. Glossary section. [http://www.nanopartikel.info/en/glossary/E]

16. Exposure environment. [http://nanopartikel.info/en/nanoinfo/materials/ carbon-nanotubes/exposure/1400-exposure-environment]

17. Criteria checklist. [http://www.nanopartikel.info/en/nanoinfo/methods/991literature-criteria-checklist]

18. The Nanotechnology Working Group. [https://wiki.nci.nih.gov/display/ICR/ Nanotechnology+Working+Group]

19. Kühnel D, Nickel C: The OECD expert meeting on ecotoxicology and environmental fate - towards the development of improved OECD guidelines for the testing of nanomaterials. Sci Total Environ 2014, 472:347-353.

20. EC: Commission Staff Working Paper - types and uses of nanomaterials, including safety aspects. SWD 2012, (288). European Commission.

21. The JRC Web Platform on Nanomaterials. [http://ihcp.jrc.ec.europa.eu/ our_activities/nanotechnology/jrcreleases-online-web-platform-onnanomaterials/

22. Schrurs F, Lison D: Focusing the research efforts. Nat Nanotechnol 2012, 7(9):546-548.

doi:10.1186/s12302-014-0021-6

Cite this article as: Kühnel et al:: Environmental impacts of nanomaterials: providing comprehensive information on exposure, transport and ecotoxicity - the project DaNa2.0. Environmental Sciences Europe 2014 26:21.

\section{Submit your manuscript to a SpringerOpen ${ }^{\circ}$ journal and benefit from:}

- Convenient online submission

- Rigorous peer review

- Immediate publication on acceptance

- Open access: articles freely available online

- High visibility within the field

- Retaining the copyright to your article 